\title{
A EDUCAÇÃO ESCOLAR SOB OS IMPACTOS DA NOVA GESTÃO PÚBLICA E DAS TECNOLOGIAS DIGITAIS*
}

\author{
Cílson César Fagiani \\ Fabiane Santana Previtali \\ Afrânio Mendes Catani
}

\begin{abstract}
"Ser idealista em educação significa justamente agir como se esse tipo de sociedade já fosse realidade. Ser realista, inversamente, significa reconhecê-la como um ideal que buscamos atingir".

Saviani, D. Escola e Democracia (2008, p.70).
\end{abstract}

\section{Introdução}

A reestruturação produtiva no mundo globalizado está originando um novo mundo do trabalho concernente a um complexo conjunto de fatores. Destacamos a difusão das tecnologias digitais, no bojo da Quarta Revolução Industrial ou Fábrica 4.0 e que traz consigo o fenômeno da uberização, um novo estágio na exploração do trabalho pelo capital, decorrente das mutações tecnológicas nos últimos tempos sob a qual são transformadas as tradicionais relações laborais. Intermediado por plataformas digitais, os aplicativos (Apps), o trabalho uberizado pode ser feito total ou parcialmente à distância, em qualquer lugar, desde que haja um computador ou celular e conexão de internet. Nesse contexto, também fortemente impulsionado pela difusão das tecnologias digitais, ocorre o aprofundamento das práticas gerenciais fundadas no toyotismo (trabalho em equipes, multifuncionalidade), das estratégias de flexibilização e terceirização, cujos discursos assentam-se na cooperação, na parceria e no empreendedorismo daquele que trabalha. Acrescenta-se ainda mais um elemento constitutivo da reestruturação produtiva do capital nos tempos atuais, que é a reforma do Estado sob as teses neoliberais e na perspectiva da Nova Gestão Pública (NGP) ou Gerencialismo (HOOD, 1995; HILL, 2003; NEWMAN; CLARKE, 2012), manifestas na centralidade do mercado, concomitantemente à redução da esfera pública como princípio orientador da sociabilidade humana.

*DOI - 10.29388/978-65-86678-84-0-0-f.195-216 
Para a classe trabalhadora como um todo e para a categoria docente em particular essas mudanças têm significado perdas substanciais, pois implicam em relações de trabalho mais instáveis, com reduzida ou nenhuma seguridade social, levando a uma crescente precarização das condições de trabalho e de vida. Cumpre dizer que a precarização é elemento constituinte do trabalho no modo de produção capitalista e por isso não é um fenômeno recente (BRAVERMAN, 1981). O dado novo que se apresenta é que a precariedade laboral não está restrita às profissões nãoqualificadas ou manuais, mas se estendeu às qualificadas, ao trabalho intelectual, assumindo um caráter sistêmico e transversal a todos as profissões (ANTUNES, 2018). Ao que parece, a promessa do fim do trabalho (MALLET, 1969; GORZ, 1987; SCHAFF, 1990) com o avanço das novas tecnologias e do trabalho intelectual não se confirmou. Contrariamente, verifica-se o incremento da classe trabalhadora no mundo hoje, mais heterogenia e transversalizada pelas diferenças de gênero, raça/etnia, idade e qualificação, mas ainda explorada pelo capital e com possibilidades reduzidas de uma vida plena fora do trabalho (ANTUNES, 2000 e 2018).

As teses de Braverman (1981) mostram-se, portanto, mais próximas da realidade: a tecnologia traz consigo uma posição de classe sob o capitalismo e por isso potencializa a exploração do trabalho para a geração do mais-valor, levando à proletarização, à precarização e desqualificação do trabalho. Segundo Antunes (2018, p. 32),

Essas novas modalidades de trabalho vêm assumindo um destaque crescente não só no mundo da produção material mas na circulação do capital e agilização das informações, esferas que são com frequência realizadas por atividades também imateriais, que ganham cada vez mais importância na reprodução ampliada do capital financeirizado, informacional e digital.

Previtali e Fagiani $(2015$, p. 66) afirmam " o que se tem presenciado é a formação de um novo modelo produtivo que tem gerado emprego associado às novas tecnologias, porém, com menores salários e em piores condições de trabalho, contribuindo enormemente para a concentração de renda".

A educação escolar não está alheia a esse novo cenário. Ao contrário, é chamada a agir na construção de um novo sujeito social que deve estar adequado ao atual patamar sócio-técnico do trabalho. Para 
tanto, faz-se necessário que ela mesma se transforme numa empresa competitiva global, voltada para obtenção de lucros a baixos custos. Hill (2003, p. 39), afirma que, sob o neoliberalismo globalizado e competitivo, é crucial o controle da educação escolar por parte dos governos posto que é nesse campo que se produz a força de trabalho que deverá ser "ideologicamente submissa, mas tecnicamente capacitada" a ser explorada pelo capital. Segundo o autor, os objetivos das reformas educacionais nos Estados Unidos e Grã-Bretanha são: a) fazer da escola uma fábrica de produção de força de trabalho para as empresas capitalistas; b) liberar as empresas privadas para lucrar com a educação e c) estabelecer as "Edubusinesses", isto é, de empresas educacionais globais que irão atuar e lucrar com a educação.

Ora, como já demonstrado por Marx (2013), os ganhos do capital assentam-se na exploração do trabalho que, por sua vez, é quem produz as mercadorias, inclusive a si mesmo como mercadoria. Nesse contexto, a reestruturação do trabalho docente torna-se peça fundamental para o planejamento da educação escolar orientada pelos conceitos de multifuncionalidade, flexibilidade e empregabilidade. E, os docentes, passam a ser considerados os principais responsáveis pelo desempenho dos estudantes, da escola e do sistema educacional, sendo exigidos para além de sua formação profissional específica, qual seja: a docência. Essa responsabilização, de acordo com seu desempenho individual e seu "amor à profissão", torna-os, alternadamente, os grandes vilões ou heróis do (in)sucesso da educação com implicações negativas em sua subjetividade, conduzindo-os a uma sensação de impotência, ao desânimo e ao adoecimento (GATTI, 2016).

O objetivo desse estudo é problematizar o trabalho docente na educação básica pública no Brasil, no estado de Minas Gerais, considerando-se o novo patamar de desenvolvimento da divisão sóciotécnica do trabalho e as reformas implementadas pelo Estado Gestor. Destaca-se que o estado de Minas Gerais foi o primeiro a implementar as reformas educacionais sob a égide da Nova Gestão Pública no governo de Aécio Neves (2003-2010), seguindo-se do governo de Antônio Anastasia (2011-2014). A pesquisa analisa dados do Instituto Nacional de Estudos e Pesquisas Educacionais Anísio Teixeira (INEP) no período 2011-2017, quanto ao gênero e idade dos professores e da prefeitura municipal de Uberlândia, nos governos de Odelmo Leão (2009-2012 e 2017-2018) e Gilmar Machado (2013-2016). Uberlândia é a segunda cidade em população 
do estado e também a segunda maior cidade do estado (IBGE, 2019). A pesquisa indica que têm havido o aprofundamento da proletarização do trabalho docente na educação básica pública ao mesmo tempo em que se ampliam as formas de intensificação e precarização das condições do trabalho e de vida.

\section{A Educação e a Nova Gestão Pública (NGP)}

A educação é um processo social amplo que coincide com o trabalho na medida em que apenas o ser humano trabalha e educa a si mesmo e aos outros na relação com o meio em que vive (SAVIANI, 2008). O animal humano é particular em relação aos outros animais porque somente ele transforma para além de adequar-se ao meio, criando com isso coisas úteis materiais e imateriais. Para Saviani (2008), o ensinar e o aprender implicam em garantir aos seres sociais o seu acesso ao acervo cultural da humanidade, isto é, à cultura material e imaterial constituída socialmente através das gerações.

Se a educação, enquanto processo social amplo, perpassa todas as esferas da vida social, desde a família, hoje, mais do que nunca, dada a complexidade da divisão sócio-técnica do trabalho, ela é sistematizada na instituição escolar. Para Gatti (2013, p. 59), "a escola é porta para outras formações e para a construção continuada da democracia e a luta pelos direitos humanos". Segundo a autora, a escola exerce em seu cotidiano o papel de escolha dos conhecimentos a serem tratados com as crianças e jovens, discernindo sobre o que ensinar, quando e em qual profundidade, visando formá-los em valores para a vida humana. Nas palavras de Gatti (2013, p. 54):

A educação escolar é um processo comunicacional específico que, para atingir suas finalidades, requer formas didáticas que possam dar suporte adequado a aprendizagens efetivas a grupos diferenciados de estudantes, em idades diferenciadas de seu desenvolvimento.

Portanto, cabe à escola formar o cidadão, do ponto de vista técnico e social. Mas, deve-se perguntar: qual cidadão se quer formar?

Para responder essa questão é preciso considerar que a escola se configura em palco de conflito político-ideológico que se faz cotidianamente, nas salas de aula, nos conselhos, nas reuniões e nos 
debates e se traduzem nos planejamentos dos currículos, em escolhas dos conteúdos, dos procedimentos pedagógicos, do material didático e das avaliações. Os professores e professoras manifestam no ato de ensinar suas histórias de vida e sua formação profissional, uma concepção de mundo e de educação. Se coloca em questão os objetivos e os fins da educação escolar: se uma educação escolar voltada para o pleno desenvolvimento da pessoa humana, preparando-a para o exercício da cidadania e para a qualificação para o trabalho ou se apenas para uma qualificação restrita, vinculada às ocupações no mercado de trabalho.

Para Saviani (2019, p. 308), o objetivo da educação escolar de formar na perspectiva do pleno desenvolvimento humano não poderá ser atingido

[...] com currículos que pretendam conferir competências para a realização das tarefas de certo modo mecânicas e corriqueiras demandadas pela estrutura ocupacional, concentrando-se ainda, e ainda de forma limitada, na questão da qualificação profissional e secundarizando o pleno desenvolvimento da pessoa e o preparo para o exercício da cidadania.

As políticas educacionais recém-implementadas, de forte cunho neoliberal a partir do governo de Michel Temer (2016-2018) e aprofundadas no governo de Jair Bolsonaro, indicam a ênfase na educação básica enquanto qualificação profissional. Haja vista a implementação de uma Base Nacional Comum Curricular em 2017 e $2018^{1}$, cujo objetivo foi nivelar e garantir a aprendizagem de um conteúdo mínimo e específico para cada etapa da educação escolar (Educação Infantil, Ensino Fundamental e Ensino Médio) no contexto nacional, fundada no desenvolvimento de dez competências gerais. No que tange especificamente a BNCC do Ensino Médio, a Associação Nacional de Pós-graduação e Pesquisa em Educação (ANPED), afirma que se trata de uma proposta curricular pautada em uma base conteudista e disciplinarista que ignora a pluralidade do mundo, das escolas e de seus sujeitos, de fast food (ANPED, 2019 s/p).

\footnotetext{
${ }^{1}$ Importante esclarecer que a Reforma do Ensino Médio contempla a BNCC. No entanto, ele contemplou uma BNCC que em 2017 não havia sido aprovada ainda. Houve, portanto, um atropelo por parte do governo o que levou ao desmembramento da BNCC, entre a parte referente ao ensino médio e outra parte referente à educação infantil e ensino fundamental, tendo sido protelada a aprovação da BNCC do ensino médio, ocorrida somente em dezembro de 2018.
} 
Conjugada a BNCC, também se encontra a Reforma do Ensino Médio em 2017, implementada sob o governo de Michael Temer. Esta reforma se justificava, segundo os seus formuladores, como meio de reduzir a alta evasão escolar vinculada a "falta de atratividade" que esta etapa da educação básica tem por ser muito teórica e pouco prática. Segundo Fagiani (2019), o que se propõe é, na verdade, uma duvidosa e suspeita preferência dos estudantes da escola pública por itinerários que incluem conteúdos e cargas horárias que direcionam as formações para uma terminalidade profissional da escolaridade nesta etapa em detrimento da continuidade para o Ensino Superior.

Convém frisar ainda a política atual de retirada de recursos públicos destinados à educação básica. Apesar do discurso do governo federal Jair Bolsonaro de dar prioridade a essa etapa da educação escolar, cerca de $\mathrm{R} \$$ 2,4 bilhões que estavam previstos para investimentos em programas da educação infantil ao ensino médio foram bloqueados em maio de 2019 (EXAME, 2019). Deve-se salientar que, acordo com o último relatório da Organização para a Cooperação e Desenvolvimento Econômico OECD (2019), o investimento por aluno na educação básica no Brasil é muito inferior ao dos outros países da organização. Nas três modalidades de educação (ensino fundamental I, ensino fundamental II e ensino médio e técnico), o Brasil investiu por aluno menos da metade do que os outros países (Tabela 1).

Tabela 1 - Investimento Anual por Aluno (em dólares - US\$)

\begin{tabular}{|c|r|r|}
\hline Modalidade & Brasil & \multicolumn{1}{c|}{ OCDE } \\
\hline Fundamental I & 3.800 & 8.600 \\
\hline Fundamental II & 3.700 & 12.200 \\
\hline Médio e Técnico & 4.100 & 10.000 \\
\hline
\end{tabular}

Fonte: Elaboração dos autores a partir de OECD (2019).

A Nova Gestão Pública cumpre um papel fundamental no reordenamento da esfera político-jurídica de regulação social em prol do capital e contra o trabalho através de estratégias que visam recompor a lucratividade daquele. Essas estratégias podem ser observadas sob três aspectos: a) privatizações diretas de setores públicos e/ou parcerias com o setor privado e assim transferência de recursos públicos para o setor privado; b) injeção de fundos públicos na revitalização de empresas privadas e c) desregulamentação das relações laborais para criação de 
condições favoráveis de aumento da produtividade do trabalho com redução de custos ao capital.

A NGP foi inicialmente implementada ao longo da década de 1990 (HOOD, 1995), sendo difundida mundialmente, incluindo-se a América Latina a partir dos anos 2000 (OLIVEIRA, 2015). Certamente esse movimento de dispersão não se faz homogêneo e linear, mas mediado, por um lado, pela posição dos países na divisão internacional do trabalho e por outro, pela dinâmica das lutas de classes internas a cada país, portanto das forças resistentes do trabalho e suas manifestações contestatórias (ANTUNES, 2018). Convém ressaltar que a adoção da NGP pelos governos não significa que o Estado deixa de ser um agente regulador. Ao contrário,

[...] o que muda é o foco da regulação que passa a ser a desregulamentação das relações entre trabalho e capital concomitantemente à abertura e garantia de novos caminhos para a acumulação do capital" (PREVITALI; FAGIANI, 2015, p. 66).

No Brasil, a reforma do Estado sob os princípios da Nova Gestão Pública assume um caráter sistêmico no governo de Fernando Henrique Cardoso (1994-2002), quando da criação do Ministério da Administração e Reforma do Estado (MARE) em 1995, pelo então Ministro Luiz Carlos Bresser Pereira sob explicita influencia da reforma do Estado implementada na Inglaterra (PREVITALI; FAGIANI, 2017). Essa politica sofreu refrações durante o governo do Partido dos Trabalhadores (PT) a partir de 2003, na medida em que se buscou implementar, mesmo sob o pressuposto neoliberal, uma perspectiva de desenvolvimento de base nacional (FREITAS, 2016).

Após o golpe institucional ao governo de Dilma Rousseff, quando Michel Temer assume a presidência da república, as práticas liberalizantes ganham novo impulso. Destaca-se a aprovação da Lei № 13.467/2017 concernente à Reforma Trabalhista, a qual autoriza diferentes modalidade de exploração do trabalho, cujo traço comum é a flexibilização e a precarização nas atividades meio e fim. Mais recentemente, sob o governo de ultradireita de Jair Bolsonaro, o trabalho sofre mais uma dura perda com a aprovação na Câmara dos Deputados da Reforma Previdenciária.

O estado de Minas Gerais sob o governo de Aécio Neves (20032010) foi um dos primeiros a adotar a proposta do gerencialismo no âmbito de seu programa denominado "Choque de Gestão". A expressão não é desprovida de intencionalidade e subjetividade. Como afirmam Fairclough e 
Melo (2012), as palavras não são neutras e carregam consigo significados que se constroem nas relações sociais e de poder. Logo, a expressão "Choque de Gestão" remete à ideia de embate, de enfrentamento e de colisão. Isto é, uma nova gestão pública que deve se impor à força aos trabalhadores do serviço público.

Nesse caminho, uma das primeiras medidas do governo foi a introdução de um sistema informatizado e integrado, assentado nas novas tecnologias digitais, de avaliação e monitoramento do desempenho individualizados dos servidores atrelando-o a resultados sistêmicos de produtividade e eficiência (MACIEL; PREVITALI, 2011; SILVEIRA; PREVITALI, 2017, PREVITALI; FAGIANI, 2019). Vale dizer que no processo educativo, a avaliação deve se fazer presente, tanto como meio de diagnóstico do processo ensino-aprendizagem quanto como instrumento de investigação da prática pedagógica, assumindo assim, uma dimensão formadora que tem como finalidade a aprendizagem, mas também que permita a uma reflexão sobre a ação pedagógica.

No entanto, segundo Silveira e Previtali (2017), as avaliações impostas aos profissionais da educação tiveram o claro objetivo de controle do trabalho via ferramentas individualizantes de gestão e responsabilização. Assim, o cerne da questão foi a desmobilização e o esgarçamento de uma consciência coletiva dos profissionais da educação pública, criando condições, objetivas e subjetivas, favoráveis às terceirizações e privatizações para os setores privados.

O caso de Uberlândia é um exemplo interessante no que tange o destino dos recursos públicos da educação básica. A rede pública educacional é formada por 185 escolas de Ensino Fundamental com 83.861 matrículas e 52 escolas de Ensino Médio com 22.921 matrículas no ano de 2018 (IBGE, 2018). No Gráfico 1 observa-se a movimentação financeira de pagamentos feitos a instituições privadas sem fins lucrativos pela prefeitura da cidade no período de 2009 até 2019, período que a administração do poder público local foi executada por dois governantes distintos, 2009/2012 e 2017/2019 por Odelmo Leão do Partido Progressista e 2013/2016 por Gilmar Machado do Partido dos Trabalhadores. 
Gráfico 1- Despesas Pagas em Educação da Prefeitura de Uberlândia em Transferência para Instituições Privadas Sem Fins Lucrativos (2009-2019).

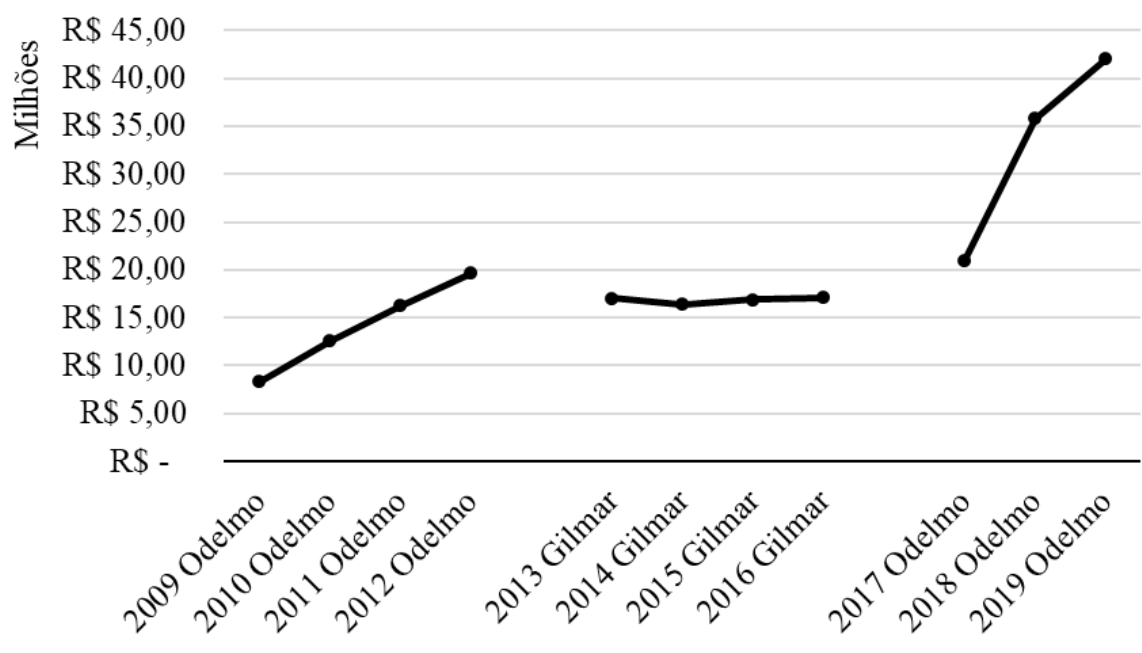

ANOS E PREFEITOS

Fonte: Elaborado pelos autores a partir de dados do Sistema de Informação sobre Orçamentos público em Educação (SIOPE, 2020).

Nos dois períodos do governo de Odelmo Leão observa-se uma crescente transferência de recursos financeiros para as instituições privadas sem fins lucrativos, de aproximadamente $R \$$ 8,0 milhões no ano de 2009 para R\$ 42,0 milhões em 2019. Já no governo de Gilmar Machado há uma redução do repasse de valores em aproximadamente $R \$ 2,0$ milhões, seguindo-se da estabilização das transferências dos recursos no patamar de $\mathrm{R} \$ 17,0$ milhões. Convém frisar que Odelmo Leão, atual prefeito, coloca-se abertamente favorável às políticas neoliberais na educação, fortemente alinhado à defesa das privatizações e redução dos investimentos públicos e apoiador do atual governo federal de Jair Bolsonaro.

\section{A (Trans)Formação do Trabalho Docente}

As inovações tecnológicas são seletivas e garantem maior controle do trabalho pelo capital através da simplificação e segmentação do trabalho, concomitantemente à objetivação do trabalho vivo na máquina, trabalho morto. Esse processo conduz à perda de autonomia dos 
trabalhadores e trabalhadoras sobre os meios e os fins do trabalho e traz como consequência a desqualificação profissional, a redução dos rendimentos do trabalho e, de forma mais geral, a degradação da vida. Isso porque, como observado por Antunes (2000; 2018), as relações sociais institucionalizadas sob o capital obstruem o potencial tecnológico numa lógica humanizante.

Conforme Previtali e Fagiani (2014, p. 760):

[...] a cada passo dado para a introdução da automação contemporânea, baseada na microeletrônica, há uma oportunidade para a destruição de formas de resistência ao controle do trabalho e à exploração.

Braverman (1981) argumenta que o trabalho intelectual em geral e do docente em particular também estariam sujeitos a um processo de proletarização mediante a racionalização técnica imposta pelo capital, levando à desqualificação e achatamento dos níveis salariais, bem como à perda de seus valores, sejam eles simbólicos ou materiais. Para o autor, a desqualificação do trabalho docente deve ser entendida como uma "perda na capacidade de realizar todas as etapas e tarefas da profissão docente e pelas formas de descontrole sobre o coletivo docente instituídas com o tecnicismo" (BRAVERMAN, 1981, p. 235).

As teses de Braverman são fundamentais para a compreensão de como a essência do controle permanece no processo de proletarização do trabalho docente no contexto das inovações tecnológica e das práticas gerencialistas do poder público. Diante desse cenário, o docente vai sendo (trans)formado, simultaneamente, objetiva e subjetivamente, num movimento histórico e dialético sob três aspectos: 1) a formação e profissionalização, 2) o processo de trabalho e 3) as relações laborais. Se o conjunto dessas mudanças é induzido a partir da base material da sociedade, expressando os interesses dominantes do capital na sua relação com o trabalho, é na esfera do Estado que ele é sistematizado e implementado através das políticas educacionais para a educação básica e superior. 


\section{Educação Básica e Suas Relações com o Ensino Superior}

O sistema educacional brasileiro é dividido em Educação Básica e Ensino Superior. A Educação Básica, a partir da Lei de Diretrizes e Bases da Educação (LDB) de 1996 (BRASIL, 1996), passou a ser estruturada por etapas e modalidades de ensino, englobando a Educação Infantil, o Ensino Fundamental e o Ensino Médio, e o ensino obrigatório dos 4 até os 17 anos a partir de 2009 (BRASIL, 2009). As mudanças no ensino superior estão intrinsecamente relacionadas à Educação Básica. Os cursos de licenciatura oferecidos pelas universidades exercem um papel preponderante na formação de professores, em nível superior, de graduação plena, pois são desses cursos que vão sair a maioria dos professores e professoras que atuarão nas escolas públicas da Educação Básica e que vão atender à maioria das crianças e jovens das classes trabalhadoras. Logo, torna-se fundamental rever os parâmetros formativos desse profissional da educação de forma que atendam às necessidades formativas das crianças e jovens no bojo da atual reestruturação produtiva do capital e da nova divisão sociotécnica do trabalho.

Nesse cenário, a educação superior passa a ser, ela mesma, revisada e reformada, quer seja em seus processos formativos, isto é, ao ensino, em especial as licenciaturas, quer seja em sua estrutura organizativa e formas de financiamento. Também aqui, os princípios da NGP passam a mediar a formação profissional e a produção do conhecimento. Para Hill (2003, p. 33), nas universidades e estabelecimentos de cursos superiores a linguagem da educação foi amplamente substituída pela linguagem do mercado, aonde os professores universitários 'entregam o produto', 'operacionalizam a entrega' e 'facilitam o aprendizado".

Catani, Esquivel e Gilioli (2007) destacam, concernentemente ao ensino, a utilização de estudantes de pós-graduação e a contratação de professores através de cooperativas de trabalho, ignorando benefícios e direitos sociais, e ainda, o estabelecimento de parcerias público-privadas e ampla utilização de cursos à distância, com economia de espaço e força de trabalho. Para os autores, "(...) são medidas que visam criar uma cultura de mercado no ambiente educacional, no qual a humanização não é a tônica, mas sim os produtos, que abarcam também os processos de aprendizagem" (CATANI; ESQUIVEL; GILIOLI, 2007, p. 59).

Ainda segundo os autores, vem ocorrendo o enxugamento da formação superior por meio do corte de verbas variados, desde de 
manutenção e renovação de prédios e vias internas, passando pelo enxugamento de força de trabalho (zeladores, auxiliares de escritório, trabalhadores da cantina, jardineiros) e chegando à redução de serviços à alunos e professores de forma a reduzir custos. Quando as atividades são imprescindíveis, recorre-se às terceirizações, comumente para empresas que negam aos funcionários os direitos trabalhistas.

Esse movimento de empresariamento da educação superior impacta diretamente na formação e profissionalização docente. Silva Jr. (2002 e 2019) aponta que o eixo da formação docente passa a privilegiar as dimensões técnica e praticista do trabalho docente ao mesmo tempo em que ocorre um processo de desvalorização das dimensões políticas e éticas da formação. Há uma formação mais aligeirada, com uma feição mais individualizada e empreendedora, colaborando para a desmobilização política desses novos profissionais, conforme os ditames do mercado de trabalho. Para Gatti (2013), a situação da formação inicial de professores apresenta problemas como currículos fragmentados, conteúdos excessivamente genéricos e grande dissociação entre teoria e prática, além de estágios mal realizados e avaliações precária, interna e externamente.

Nesse ínterim, convém apontar as mais recentes mudanças nas políticas para o ensino superior sob o governo Bolsonaro, eleito em 2018 concernente ao "Projeto Future-se". Segundo Leher (2019), o projeto consubstancia o novo momento da acumulação capitalista no Brasil ao legitimar o fim da vinculação constitucional de verbas para a educação superior à revelia da Constituição Federal.

\section{O Processo de Trabalho}

O segundo aspecto a ser destacado é concernente ao processo de trabalho, isto é, às atividades no local de trabalho. $O$ trabalho docente vem sendo submetido a um conjunto de novas tarefas, entre elas, supervisão, orientação, coordenação, juntamente com a função da docência, aumentando o trabalho burocrático para prestação de contas do ensino, o que contribui para a intensificação do trabalho (GARCIA; ANDON, 2009; FRIGOTTO, 2012). Os docentes ainda são estimulados a "captar" recursos através de projetos desenvolvidos em parcerias com setores privados para o complemento orçamentário (LIMA et al, 2013). Silveira e Previtali (2017), ao analisarem o estado de Minas Gerais, evidenciam a introdução dos novos modelos de gestão e controle do trabalho baseadas no desempenho 
individual e vinculadas à metas e resultados e pagamentos diferenciados, o que contribuiu para a individualização do trabalho e para esgarçamento do sentimento de solidariedade de classe, dificultando as ações coletivas. Para Gatti (2016, p. 168), a construção do novo perfil do profissional interage diretamente com as mudanças na sua formação.

As condições do exercício profissional dos professores interagem com as condições de formação em sua constituição identitária profissional, conduzindo a formas de atuação educativas e didáticas que se refletem em seu processo de trabalho. Daí a necessidade de se repensar entre nós os processos formativos de professores, de um lado, e sua carreira, de outro.

Hypolito, Veira e Pizzi (2009), por sua vez, realçam a redução de tempo de descanso na jornada de trabalho, falta de requalificação na área de atuação por falta de tempo, dependência de materiais formulados por terceiros, despolitização das ações conjuntas, introdução de tecnologias para suprir as carências humanas na formação, gerando o aligeiramento e precarização da formação e manipulação das consciências. Maciel e Previtali (2011) chamam a atenção ao processo de sujeição da subjetividade docente através de mecanismos informacionais e burocráticos de controle que levam à objetivação do seu saber em procedimentos preestabelecidos nos manuais de ensino, nas apostilas, nas avaliações já preparadas pela administração escolar e governamental.

\section{As Relações Laborais}

No que se refere ao terceiro aspecto, as relações laborais, cabe destacar o expressivo número de docentes que trabalha em mais de uma escola e leciona para grande número de alunos por turma, recebendo em contrapartida uma remuneração menor que o de outros profissionais com nível de formação equivalente ou mesmo inferior (ALVES; PINTO, 2011). Merece destaque o crescimento dos contratos temporários de trabalho que fazem com que os professores e professoras migrem frequentemente de uma escola para outra ao término de cada vínculo o que gera um descompasso no processo de ensino-aprendizagem.

Os Gráficos 2 e 3 apresentam os dados correspondentes aos tipos de vínculos Temporário e Efetivo na rede pública de educação, em nível de 
Brasil, região Sudeste e estado de Minas Gerais, de acordo com o Inep entre os anos 2011 e 2017. Observa-se no Gráfico 2 que houve um aumento significativo dos docentes com vínculo Temporário, sendo de $15 \%$ no Brasil, $19 \%$ na região Sudeste e $63 \%$ no estado de Minas Gerais. Já com relação ao vínculo Efetivo, verifica-se que este passou por um aumento de $6 \%$ no Brasil e $8 \%$ na região Sudeste e sofreu uma redução de $17 \%$ no estado de Minas Gerais, conforme Gráfico 3.

Apesar do aumento ocorrido no caso do vínculo Efetivo no Brasil e na região Sudeste, observa-se claramente a tendência à diminuição desse tipo de vínculo já que os aumentos, em porcentagens, no Brasil e na região Sudeste foram maiores para o tipo de vínculo Temporário. Merece destaque ainda o ocorrido no estado de Minas Gerais onde observa-se o aumento de $63 \%$ no tipo de vínculo Temporário e uma redução de $17 \%$ do vínculo do tipo Efetivo.

Gráfico 2 - Número total de vínculos do tipo Temporário dos docentes das instituições escolares do Brasil, da região Sudeste e do estado de Minas Gerais

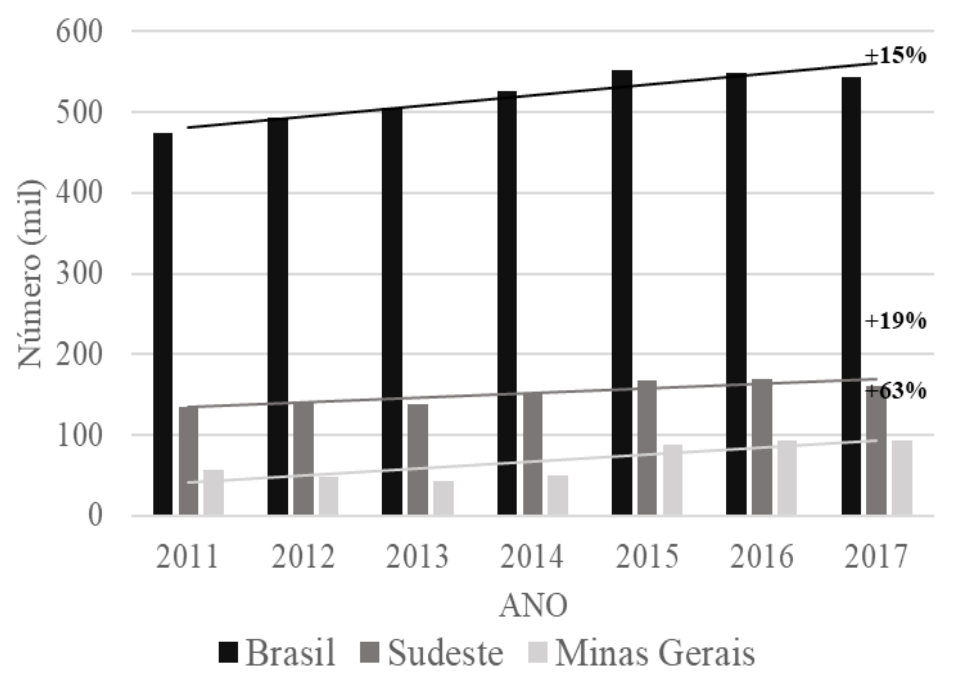

Fonte: Produção própria a partir de dados do Inep (2011-2017). 
Gráfico 3 - Número de vínculos do tipo Efetivo dos docentes das instituições escolares do Brasil, da região Sudeste e do estado de Minas Gerais.

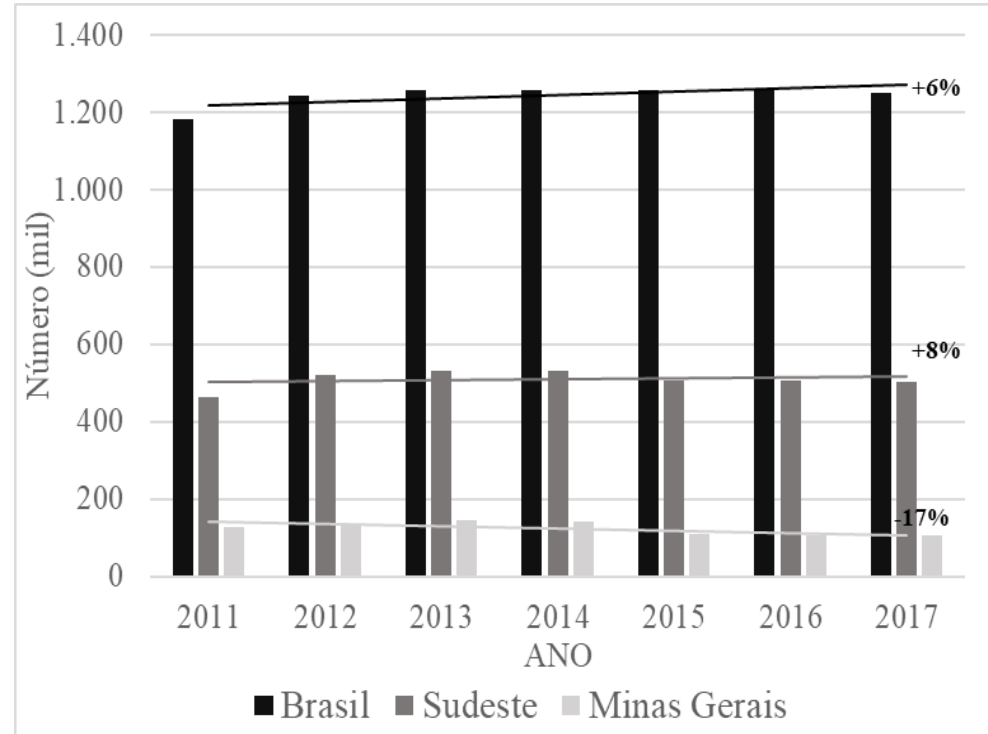

Fonte: Produção própria a partir de dados do Inep (2011-2017).

Concernente ainda à precarização das relações de trabalho docente importa destacar o aumento das terceirizações através das parceiras com ONGs, OSs e parcerias públicos-privadas, ao mesmo tempo que ocorre a redução de concursos públicos (PEREIRA, 2018).

Em Uberlândia, em 2018 já existiam 32 escolas de Educação Infantil com atendimento em convênio com instituições privadas, quando a prefeitura avançou com essa prática para o Ensino Fundamental e realizou a terceirização da administração das Escolas Municipais Professor Luizmar Antônio dos Santos no bairro Monte Hebron e Professora Rosa Maria Melo no bairro Pequis, localizados na periferia da cidade em 2018 (LEMOS, 2018). Acrescenta-se ainda que a Câmara Municipal aprovou o repasse de R\$ 3,6 milhões para a Fundação Filadélfia assumir a administração de escolas municipais e também mais $R \$$ 5,2 milhões para as Organizações Sociais "Missão Sal da Terra" e "Grupo Salva Vidas" se incumbirem das escolas de Educação Infantil dos bairros já citados, além dos bairros Shopping Park e Chácaras Panorama, também localizados na periferia (ALEIXO, 2018). 


\section{Conclusão}

A educação não é uma mercadoria para ser comprada e vendida. Pode-se comprar os meios para a educação, mas não o aprendizado em si. O trabalho docente, elemento central do processo educacional escolar é sui generis na medida em que implica na interação entre professores e estudantes, com objetivos determinados, é mediado por conhecimentos e técnicas específicas que possibilitam o seu controle pelo profissional docente. Traz, portanto, em si, por sua própria natureza, a atividade criadora e transformadora do ser social. O desejo do capital é exatamente aprisionar essa ilimitada capacidade criadora e transformadora aos ditames do próprio capital, tornando o docente num mero robô, uma máquina com "inteligência", se é que podemos usar esse termo, mas precisemos então: inteligência formatada de acordo com os interesses economicistas. Assim, sob a ótica do capital, torna-se vital controlar o trabalho docente desde sua formação, passando por sua atuação profissional e condições de trabalho. Ademais, ao desqualificar a educação como um direito, tomar a estrutura educacional e usá-la para obtenção de lucro e não mais para a formação do sujeito social.

O que se observa como tendência nas políticas educacionais brasileiras é exatamente a ênfase na qualificação profissional limitada, como expressa bastante bem a reforma do ensino médio sob o governo Temer (2016-2018). Há que se destacar que as reformas políticoeducacionais aqui implementadas seguem uma tendência mundial. Mas os países inserem-se de forma específica nesse cenário, de acordo com a posição que ocupam na divisão internacional do trabalho e o Brasil ingressa sob a marca da determinação e subserviência aos ditames dos países centrais, o que promove lucratividade ao capital privado nacional, mas, em contrapartida, a destruição do trabalho e uma brutal desigualdade social.

As tecnologias digitais nos processos educacionais implicam, tendencialmente, na desqualificação do trabalho docente, pois objetivam nos processos informatizados o conhecimento e a experiência, portanto, o "saber-fazer" docente. Aumenta-se o trabalho morto em relação ao trabalho vivo. Este pode ser agora, subempregado e, no limite, descartável. Resistir a esses imperativos é tarefa fundamental de nosso tempo. A resistência somente é possível mediante o resgate das lutas coletivas. Como afirma Antunes (2018), a classe trabalhadora é ontologicamente decisiva 
pelo papel que exerce na produção do valor e é na própria materialidade imiscuída em sua subjetividade que está o seu potencial de resistência.

\section{Referências}

ALEIXO, C. Aulas nas escolas fundamentais dos bairros Pequis e Monte Hebron começam nesta terça em Uberlândia. G1 Triângulo Mineiro, 27 de fevereiro de 2018. Disponível em: https://g1.globo.com/mg/triangulomineiro/noticia/aulas-nas-escolas-fundamentais-dos-bairros-pequis-emonte-hebron-comecam-nesta-terca-em-uberlandia.ghtml. Acesso em 10 jun. 2018.

ALVES, T.; PINTO, J. M. Remuneração e Características do Trabalho Docente no Brasil: um aporte. Outros Temas. 606-639 v.41 n.143 maio/ago. 2011. Disponível em: http://www.scielo.br/pdf/cp/v41n143/a14v41n143.pdf. Acesso em 15 maio. 2016.

ANTUNES, R. Os Sentidos do Trabalho. São Paulo: Boitempo. 2000.

ANTUNES, R. O Privilégio da Servidão. São Paulo: Boitempo. 2018.

ANPED. Posição da ANPEd sobre texto referência - DCN e BNCC para formação inicial e continuada de Professores da Educação Básica. 2019. Disponível em: http://www.anped.org.br/news/posicao-da-anped-sobretexto-referencia-dcn-e-bncc-para-formacao-inicial-e-continuada-de, de 09 de outubro de 2019. Acesso em 11 out. 2019.

BRASIL. Emenda Constitucional n. 59. Publicada em 11 de novembro de 2009. Disponível em:

http://www.planalto.gov.br/ccivil_03/constituicao/Emendas/Emc/emc59.ht m .Acesso em 19 fev. 2017.

BRASIL. Lei de Diretrizes e Bases da Educação Nacional. Lei número 9394, 20 de dezembro de 1996. Disponível em: http://www.planalto.gov.br/ccivil_03/LEIS/L9394.htm. Acesso em 10 jun. 2018. 
BRAVERMAN, H. Trabalho e Capital Monopolista. Rio de Janeiro: Zahar Eds. 1981.

CATANI, A. M.; ESQUIVEL, J. C. C.; GILIOLI, R. de S. P. Reformas da educação superior no Chile, no Brasil e em Portugal: uma abordagem comparativa. Diálogo Educ., Curitiba, v. 7, n. 21, p.49-63, maio./ago. 2007

EXAME. Mec contraria discurso e tira verba da educação básica. 2019. Disponível em: https://exame.abril.com.br/brasil/mec-contraria-discurso-etira-verba-da-educacao-basica-alem-de-faculdades/. Acesso em 13 set. 2019.

FAGIANI, C.C. Brasil e Portugal: qual a formação do jovem trabalhador no século XXI? Uberlândia: Navegando. 2019.

FAGIANI, C. C., PREVITALI, F. S. A nova configuração da classe trabalhadora no século XXI: qualificação e precarização. Revista Ciências do Trabalho. Vol. 3. 2014. p. 53 - 67. Disponível em:

https://rct.dieese.org.br/index.php/rct/article/view/47. Acesso em 10 mar. 2019.

FAIRCLOUGH, N.; MELO, I. F. de. Análise Crítica do Discurso como método em pesquisa social científica. Linha D'Água, São Paulo, v. 25, n. 2, p. 307329, dec. 2012. Disponível em:

https://www.revistas.usp.br/linhadagua/article/view/47728/51460. Acesso em: 02 fev. 2017. p. 307-329.

FREITAS, L. C. de. Três Teses sobre as Reformas Empresariais da Educação: perdendo a ingenuidade. Cad. Cedes, Campinas, v. 36, n. 99, p. 137-153, maio-ago., 2016. Disponível em:

https//www.scielo.br/pdf/ccedes/v36n99/1678-7110-ccedes-36-9900137.pdf. Acesso 20 ago. 2017.

FRIGOTTO, G. Educação, Crise do Trabalho Assalariado e do Desenvolvimento: teorias em conflito, In: FRIGOTTO, Gaudêncio (Org).

Educação e Crise do Trabalho. Petrópolis, Rio de Janeiro: Vozes. 2012. p. 25 - 53. 
GARCIA, M. M. A., ANADON, S. B. Reforma educacional, intensificação e autointensificação do trabalho docente. Educação \& Sociedade. Campinas, vol. 30, n. 106, p. 63-85, jan./abr. 2009. Disponível em http://www.cedes.unicamp.br. Acesso em 28 ago. 2014.

GATTI, B. A. Formação de Professores: Condições e Problemas Atuais. Revista Internacional de Formação de Professores (RIFP), Itapetininga, v. 1, n.2, p. 161-171, 2016. Disponível em:

http://itp.ifsp.edu.br/ojs/index.php/RIFP/article/view/347/360. Acesso em 15 fev. 2017.

GATTI, B. A. Educação, Escola e Formação de Professores: políticas e impasses. Educar em Revista, Curitiba, Brasil, n. 50, p. 51-67, out./dez. 2013. Disponível em: http://www.scielo.br/pdf/er/n50/n50a05.pdf. Acesso em 15 fev. 2020

GORZ, A. Adeus ao Proletariado. Rio de Janeiro: Forense. 1987.

HILL, D. O Neoliberalismo Global, a Resistência e a Deformação da Educação. Currículo sem Fronteiras, v. 3, n. 2, p. 24-59, jul./dez. 2003. Disponível em:

http://www.curriculosemfronteiras.org/vol3iss2articles/hill.pdf. Acesso em 12 jun. 2014.

HOOD, C. The "New Public Management" in the 1980s: Variations on a theme. Accounting, Organizations and Society, Vol. 20, No. 2/3, p. 93109.1995. Disponível em: https://www.sciencedirect.com/science/article/pii/0361368293E0001W. Acesso em 14 mar. 2000.

HYPOLITO, A. M.; VIEIRA, J. S.; PIZZI, L. C. Reestruturação Curricular e Autointensificação do Trabalho Docente. Currículo sem Fronteiras, v.9, n.2, p.100-112, Jul/Dez 2009. Disponível em:

http://www.curriculosemfronteiras.org/vol9iss2articles/hypolito-vieira pizzi.pdf. Acesso em 10 mar. 2010. 
IBGE. Cidades. Uberlândia. 2018. Disponível em:

https://cidades.ibge.gov.br/brasil/mg/uberlandia/panorama. Acesso em 10 set. 2019.

INEP. INSTITUTO NACIONAL DE ESTUDOS E PESQUISAS EDUCACIONAIS ANÍSIO TEIXEIRA. InepData. 2011-2017. Disponível em:

http://portal.inep.gov.br/inep-data. Acesso em 10 fev. 2019.

LEHER, R. Análise preliminar do "Future-se" indica a refuncionalização das universidades e institutos federais. Esquerda Online, 25 de julho de 2019. Disponível em:

https://esquerdaonline.com.br/2019/07/25/leia-a-analise-de-robertoleher-da-ufrj-sobre-o-future-se/. Acesso em 10 out. 2019.

LEMOS, V. Educação vai terceirizar escolas do Pequis e Hebron. Diário de Uberlândia. 11 de janeiro de 2018. Disponível em:

https://diariodeuberlandia.com.br/noticia/15146/educacao-vai-terceirizarescolas-do-pequis-e-hebron . Acesso em 13 jan. 2018.

LIMA, A. B. et al. A Escola na Eterna Dimensão conflitual: ser conservação e ter transformação. In: LIMA, Antonio Bosco de; FREITAS, Dirce Neri T. de (Orgs). Políticas Sociais e Educacionais: cenários e gestão. Uberlândia:

Edufu. 2013. p. 267-282.

MACIEL, R. M.; PREVITALI, F. S. Impacto das Políticas Públicas do Trabalhador da Educação na Rede Estadual de Ensino de Patos de Minas / MG em 2011. Revista Labor. vol. 1, n. 6. p. 326-343. 2011. Disponível em: http://www.scielo.br/scielo.php?

script=sci_nlinks\&pid=S16793951201400040000300017\&lng=en . Acesso em 20 jan. 2012.

MALLET, S. La Nouvelle Classe Ouvriere. Paris: Seuil. 1969.

MARX, K. O Capital. v.1. São Paulo. Boitempo. 2013.

NEWMAN, J.; CLARKE, J. Gerencialismo. Educ. Real. [online]. vol.37, n.2.

p.353-381. 2012. Disponível em: http://dx.doi.org/10.1590/S2175-

62362012000200003. Acesso em 14 jun. 2014. 
OECD. Education at a Glance 2019 Indicators. OECD Publishing. Paris. 2019. Disponível em: https://doi.org/10.1787/f8d7880d-en. Acesso em 10 jun. 2019.

OLIVEIRA, D. A. Nova Gestão Pública e Governos Democrático-Populares: contradições entre a Busca da Eficiência e a ampliação do direito à Educação. Educ. Soc., Campinas, v. 36, no. 132, p. 625-646, jul.-set., 2015. Disponível em: http://www.scielo.br/pdf/es/v36n132/1678-4626-es-36132-00625.pdf. Acesso em 10 nov. 2015.

PEREIRA, L. D. S. Crise nas Licenciaturas: o novo perfil do professor da educação básica no Brasil sob a égide do neoliberalismo. Dissertação [Mestrado em Educação]. Faculdade de Educação da Universidade Federal de Uberlândia. 2018. Disponível em:

https://repositorio.ufu.br/handle/123456789/21098. Acesso em 14 out. 2019.

PREVITALI, F. S.; FAGIANI, C.C. Estado de Bem-Estar Social, Neoliberalismo e Estado Gestor: aproximações globais. In: LUCENA, Carlos; PREVITALI, Fabiane Santana; LUCENA, Lourdes. (Orgs.). A Crise da Democracia Brasileira. Uberlândia: Ed. Navegando. p. 79-98. 2017. Disponível em: https://www.editoranavegando.com/. Acesso em 10 out. 2019.

PREVITALI, F. S.; FAGIANI, C. C. Inovação Tecnológica e Trabalho Terceirizado: as bases do controle do capital no século XXI. Direitos, Trabalho e Política Social. , v.1, p.102 - 128, 2015. Disponível em: http://revista91.hospedagemdesites.ws/index.php/rdtps/issue/view/1. Acesso em 10 out. 2019.

PREVITALI, F. S., FAGIANI, C. C. Organização e Controle do Trabalho no Capitalismo Contemporâneo: a relevância de Braveman. Cadernos EBAPE.BR. v.12, n. 4. 2014. p. 759-769. Disponível em: http://bibliotecadigital.fgv.br/ojs/index.php/cadernosebape/issue/view/ 2119. Acesso em 18 jun. 2019. 
PREVITALI, F. S.; FAGIANI, C.C. Trabalho e Precarização Docente sob o Estado Gestor no Brasil. In: PREVITALI, Fabiane Santana et al (Orgs). Desafios do Trabalho e Educação no Século XXI: os 100 anos da Revolução Russa. V. 2. Uberlândia: Navegando. 2019. p. 161-182.

SAVIANI, D. Escola e Democracia. Edição Comemorativa. Campinas: Autores Associados, 2008.

SAVIANI, D. Pedagogia Histórico-Crítica, Quadragésimo Ano Novas Aproximações. Campinas: Autores Associados, 2019.

SCHAFF, A. A Sociedade Informática. Rio de Janeiro: Brasiliense. 1990.

SIOPE. Sistema de Informação sobre Orçamentos Públicos em Educação, 2020. Disponível em:

https://www.fnde.gov.br/siope/dadosInformadosMunicipio.do?

acao $=$ pesquisar $\&$ pag $=$ result $\& a n o s=2017 \&$ periodos $=6 \&$ cod_uf $=31 \&$ municipi os $=317020 \&$ admin $=3 \&$ planilhas $=125 \&$ descricaoltem $=*+$ Consolidado + de $+D$ espesa\&descricaodoltem ${ }^{*}+$ Consolidado+de+Receita\&nivel. Acesso em 19 fev. 2020.

SILVA JR. J. R., KATO, F. B. G., EWERTON, J. A., FARGONI, E. H. E. Americanismo, o Novo Marco da Ciência, Tecnologia e Inovação: sequestro do fundo público pelo capital financeiro. In: PREVITALI, Fabiane Santana; FAGIANI, Cílson César; LUCENA, Carlos Alberto (Orgs). Desafios do Trabalho e Educação no Século XXI: 100 anos da Revolução Russa. v. 2. Uberlândia: Navegando. 2019. p. 165-188.

SILVA JR, J. R. Reforma do Estado e da educação no Brasil de FHC. São Paulo: Xamã, 2002.

SILVEIRA, E. R. M da; PREVITALI, F. S. Trabalho docente e políticas educacionais: um estudo sobre o controle do trabalho docente na rede estadual de ensino de minas gerais em Uberlândia - a partir de 2003.

Revista Inova Ciência \& Tecnologia. v. 3, n.2, jul./dez., 2017. Disponível em: http://periodicos.iftm.edu.br/index.php/inova/article/view/244. Acesso em 12 fev. 2018. 